\title{
LIVROS DIDÁTICOS DE HISTÓRIA DA REDE SALESIANA DE ESCOLAS: prescrições e usos ${ }^{1}$
}

\author{
Clarícia Otto*
}

\author{
Geane Kantovitz $^{* *}$
}

\section{Resumo}

O livro didático é um dos dispositivos da educação escolar marcado por um emaranhado conjunto de interesses dos autores, editores, gestores institucionais, entre outros envolvidos no processo de sua fabricação. É um artefato impresso que se constitui em fonte inesgotável de pesquisa, especialmente, no que tange aos usos feitos por professores e estudantes. Assim, neste artigo, objetiva-se apresentar questões em torno da coleção de livros didáticos de História para o ensino médio da Rede Salesiana de Escolas (RSE), em Santa Catarina: contexto de fabricação, prescrições por parte da Rede e autores, sua utilização por cinco professores e 173 estudantes do ensino médio. Observou-se que o professor como mediador do processo de ensino e aprendizagem influi na forma como os estudantes se apropriam e produzem representações acerca do livro didático e do conhecimento histórico.

Palavras-chave: Livro Didático. Ensino de História. Rede Salesiana de Escolas.

\section{HISTORY TEXT-BOOKS OF THE SALESIAN SCHOOLS NETWORK: requirements and uses}

\begin{abstract}
The teaching text book is one of the education tools marked by a confuse set of interests linked to authors, editors, institution managers, among others involved in the process of manufacturing. It is a printed device being a permanent source of research, specially related to the uses did by teachers and students. Thus, in this article, the aim is to present issues about the History text book collection for the high school teaching of the Salesian School Network (RSE in portuguese), in Santa Catarina state: manufacturing context, Salesian net and authors requirements, its utilizations by 5 teachers and 173 high school students. It was observed that the teacher as facilitator of the process teaching-learning, do influence the way students take ownership and produce representations on the text-book and the historical knowledge.
\end{abstract}

Keywords: Text-book; History Teaching; Salesian Schools Network.

\footnotetext{
${ }_{*}^{1}$ Esta pesquisa contou com financiamento do CNPq na modalidade bolsa de estudo.

Doutora em História e Professora da Universidade Federal de Santa Catarina. E-mail: clariciaotto@yahoo.com.br

** Mestre em Educação pela Universidade Federal de Santa Catarina. Professora do Centro Universitário Leonardo da Vinci, da Faculdade Metropolitana de Rio do Sul, do Colégio Dom Bosco e da rede pública (Estado de Santa Catarina). E-mail: geaneks@hotmail.com
} 
Mas o mercado do livro escolar, para além dos aspectos económicos e sociais de comercialização, distribuição, circulação, aquisição, empréstimo, é também afectado por factores de regulação e pelas circunstâncias históricas no que se refere às políticas curriculares e à mediatização do acesso por intervenção das instituições escolares e dos professores, entre outros (MAGALHÃES, 2006, p. 7-8).

A coleção de livros didáticos de História do ensino médio da Rede Salesiana de Escolas (RSE) é composta por três volumes (Imagens 1, 2 e 3). Esses livros são utilizados em todas as escolas salesianas do Brasil, desde $2005 .^{2}$

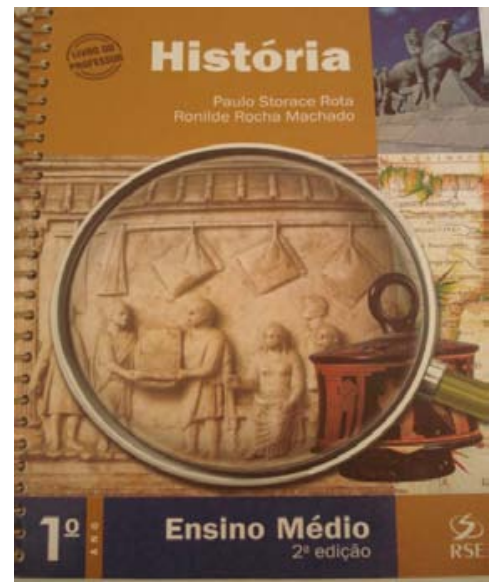

Imagem 1 - Capa do volume 1

Fonte: Colégio Dom Bosco, Rio do Sul (SC) ${ }^{3}$

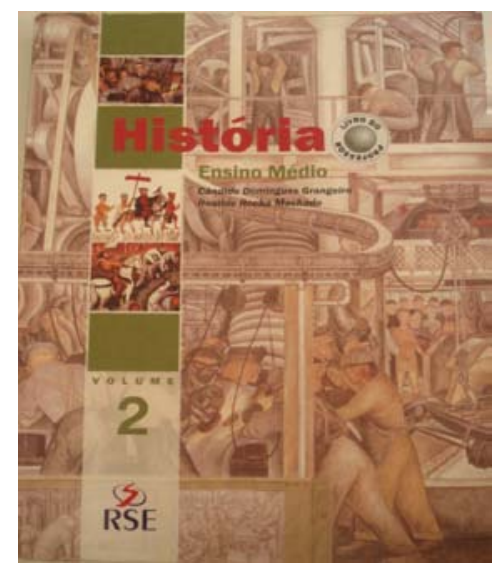

Imagem 2 - Capa do volume 2

Fonte: Colégio Dom Bosco, Rio do Sul (SC) ${ }^{4}$

\footnotetext{
${ }^{2}$ As escolas da RSE no Brasil estão organizadas em seis polos: Manaus (AM), Recife (PE), Campo Grande (MS), Belo Horizonte (MG), São Paulo (SP) e Porto Alegre (RS). As cinco escolas de Santa Catarina fazem parte do polo de Porto Alegre. As escolas da Rede são particulares e de cunho religioso católico em virtude de pertencerem a congregações religiosas salesianas.

${ }^{3}$ ROTA, Paulo Storace; MACHADO, Ronilde Rocha. História: ensino médio, $1^{\circ}$ ano. 2. ed. Brasília: CIB Cisbrasil, 2009. 268 p. (Coleção RSE, MH1A).

${ }^{4}$ GRANGEIRO, Cândido Domingues; MACHADO, Ronilde Rocha. História: ensino médio, $2^{\circ}$ ano. Brasília: CIB - Cisbrasil, 2005. 275 p. (Coleção RSE, MH2A).
} 


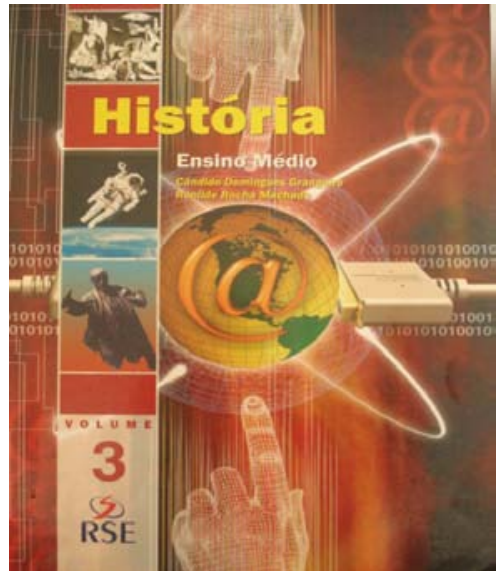

Imagem 3 - Capa do volume 3

Fonte: Colégio Dom Bosco, Rio do Sul (SC) ${ }^{5}$

De acordo com Bisewski (2008), a RSE, no Brasil, surgiu com base em um processo desencadeado pelas Escolas Salesianas na América (ESA), nas quais foi dado início ao trabalho em Rede. O primeiro encontro entre as ESAs foi realizado em 1994, na cidade de Cumbaya (Cumbaya I), Equador. Em 2001, no mesmo país, aconteceu o segundo encontro (Cumbaya II). Foi nesse segundo encontro que os padres Salesianos de Dom Bosco (SDB) e as religiosas Filhas de Maria Auxiliadora (FMA) iniciaram o processo de uma ação em prol de uma Rede Educativa entre suas respectivas instituições de ensino. Assim, em 2002, na Conferência das Inspetorias dos Salesianos de Dom Bosco do Brasil (CISBRASIL) e na Conferência das Inspetorias das Filhas de Maria Auxiliadora do Brasil (CIB), a Rede Salesiana de Escolas foi oficializada.

Com a integração das escolas salesianas à Rede, surgem direcionamentos para uma educação baseada nos princípios de Dom Bosco, fundador da Congregação. ${ }^{6}$ Entre 2002 e 2005 foi elaborado um novo Projeto Pedagógico para a RSE, também denominado Marco Referencial. O Projeto Pedagógico apresenta as diretrizes gerais da educação salesiana e de como deve ser conduzido o processo escolar para a concretização da proposta em todas as escolas associadas à Rede. Há uma intenção planejada de homogeneizar o trabalho pedagógico dos docentes:

\footnotetext{
${ }^{5}$ GRANGEIRO, Cândido Domingues; MACHADO, Ronilde Rocha. História: ensino médio, $3^{\circ}$ ano. Brasília: CIB - Cisbrasil, 2006. 336 p. (Coleção RSE, MH3A).

${ }^{6}$ João Melchior Bosco (1815-1888) nasceu em Turim (Itália). É popularmente conhecido como Dom Bosco. Em 1859, fundou a Pia Sociedade São Francisco de Sales, mais conhecida como Salesianos de Dom Bosco (SDB). Entre as obras dos Salesianos estão as escolas e os serviços beneficentes. Disponível em: <http://www.paginaoriente.com/santos/crdb3101.htm>. Acesso em: 29 abr. 2012.
} 
O professor deve atuar com base num projeto coerente e coletivamente elaborado, evitando-se, assim, que estilos individuais acabem por determinar o funcionamento das escolas, especialmente quando experiências de trabalho integrado e cooperativo inexistem na realidade que se deseja modificar (PROJETO PEDAGÓGICO, 2005, p. 18).

Os livros didáticos são produtos resultantes de políticas institucionais imbricadas nesse projeto. São produzidos por equipes contratadas pela própria Rede e igualmente impressos pelas Escolas Profissionais Salesianas (SP) e publicados pela editora CIB - Cisbrasil, Brasília (DF). Por tratar-se de uma rede de ensino privado, esses livros não são submetidos ao processo de avaliação do Programa Nacional do Livro Didático (PNLD). ${ }^{7}$

As respectivas instituições salesianas existentes no estado de Santa Catarina, nas quais a coleção está sendo utilizada são: Colégio Auxiliadora, em Campos Novos; Colégio Dom Bosco, em Rio do Sul; Instituto Maria Auxiliadora, igualmente situado em Rio do Sul; Colégio São Paulo, em Ascurra e Colégio Salesiano Itajaí, na cidade de Itajaí. A pesquisa foi desenvolvida com estudantes das terceiras séries do ensino médio. Essa escolha justifica-se por ser a última turma a utilizar o livro didático correspondente ao processo de implantação da coleção. ${ }^{8}$

O livro didático é considerado, pela RSE, o instrumento metodológico mais importante a ser utilizado pelos professores. É parte integrante do processo de ensino e aprendizagem e principal componente da cultura material da Rede. Desde 2005, o livro didático é tido como o principal instrumento na concretização da unidade pedagógica e metodológica no cotidiano das escolas salesianas do Brasil.

Ao se pensar no ensino de História, nos usos dos livros didáticos, nas prescrições da Rede para a constituição de determinada cultura escolar, surgem alguns questionamentos: Os professores abordam todo o conteúdo do livro didático? Quais são as representações e apropriações de estudantes e professores? Como trabalham com livros que possuem 268 (volume 1); 275 (volume 2) e 336 (volume 3) páginas em poucas aulas semanais? (Quadro 1).

\footnotetext{
${ }^{7}$ O PNLD, no Brasil, passou a vigorar em 1985. Por meio desse Programa o governo federal compra e distribui livros didáticos às escolas públicas do país. Desde 1996 o PNLD também passou a reunir especialistas para a avaliação dos livros (CASSIANO, 2007).

${ }^{8}$ Com a finalidade de manter o anonimato, quando da transcrição de fragmentos de narrativas de estudantes e professores, utiliza-se "Narrativa de estudante” e "Professor I, II, III, IV e V”. De igual modo, as escolas são identificadas por "Escolas I, II, III, IV e V”.
} 
Quadro 1 - Número de aulas semanais de História no ensino médio da RSE em SC.

\begin{tabular}{|l|l|l|l|}
\hline Identificação & $\begin{array}{l}\text { Carga horária na } \\
1^{\mathrm{a}} \text { série }\end{array}$ & $\begin{array}{l}\text { Carga horária } \\
\text { na 2 } \text { série }^{\mathrm{a}}\end{array}$ & $\begin{array}{l}\text { Carga horária } \\
\text { na 3 } \text { série }^{\mathrm{a}}\end{array}$ \\
\hline Colégio Dom Bosco & 2 aulas & 2 aulas & 1 aula \\
\hline Instituto Maria Auxiliadora & 2 aulas & 2 aulas & 2 aulas \\
\hline Colégio Salesiano Itajaí & 2 aulas & 2 aulas & 3 aulas \\
\hline Colégio Auxiliadora & 2 aulas & 2 aulas & 2 aulas \\
\hline Colégio São Paulo & 2 aulas & 2 aulas & 2 aulas \\
\hline
\end{tabular}

Fonte: Currículos das referidas escolas.

\section{Cultura escolar e representação}

De acordo com Chartier (1990, p. 17), as representações sociais são construídas e “embora aspirem à universalidade de um diagnóstico fundado na razão, são sempre determinados pelos interesses de grupo que as forjam”. As discussões do autor seguem o caminho de se compreender não somente as práticas, mas também as percepções e discursos, os quais também produzem estratégias e práticas.

A noção de representação permite articular três registros de realidade:

Por um lado, as representações coletivas que incorporam nos indivíduos as divisões do mundo social e organizam os esquemas de percepção a partir dos quais eles classificam, julgam e agem; por outro, as formas de exibição e de estilização da identidade que pretendem ver reconhecida; enfim, a delegação a representantes (indivíduos particulares, instituições, instâncias abstratas) da coerência e da estabilidade da identidade assim afirmada (CHARTIER, 2002, p. 11).

Dessa forma, a apropriação é uma operação de produção que, embora não fabrique nenhum objeto, assinala a sua presença pela maneira de utilizar os produtos impostos. As práticas de apropriação são o contraponto às operações (estratégias) que visam disciplinar e regular o consumo cultural. A apropriação, nesse sentido, aponta para uma "liberdade criadora” que possibilita uma negação da imposição total de sentidos visando a uma "história social dos usos e das interpretações, relacionados às suas determinações fundamentais e inscritos nas práticas específicas que os produzem” (CHARTIER, 2002, p. 68). Assim, compreender o processo educacional instaurado na RSE implica considerar aspectos que fazem parte dessa cultura escolar, entre eles os materiais didáticos, as práticas educativas e os dispositivos de inculcação de valores culturais, sociais e religiosos. ${ }^{9}$

\footnotetext{
${ }^{9}$ Veiga (2002, p. 91) indica que, para Foucault, “a escola não é o dispositivo, mas a escolarização, uma rede heterogênea de elementos que lhe dá visibilidade e ocultamento, nas formas discursivas e não discursivas. É uma estratégia inscrita em jogos de poder, ligada a configurações de saber que deles nascem e também os condicionam; enfim, a escolarização como estratégia de poder”.
} 
Para Julia (2001, p. 10), a cultura escolar é “um conjunto de normas que definem conhecimentos a ensinar e condutas a inculcar, e um conjunto de práticas que permitem a transmissão desses conhecimentos e a incorporação desses comportamentos”. O autor aborda a cultura escolar de forma ampla, considerando as práticas e conteúdos como um movimento que a cada espaço e em cada período histórico atende a especificidades próprias de instituições com interações sociais próprias e culturas diversificadas. Nesse sentido, a cultura escolar evidencia que a escola não é somente um lugar de transmissão de conhecimentos, mas é, ao mesmo tempo, um lugar de inculcação de comportamentos.

Forquin (1992, p. 33-34), ao tratar dos imperativos na reorganização dos saberes, afirma que

a cultura escolar apresenta-se assim como uma cultura segunda com relação à cultura de criação ou de invenção, uma cultura derivada e transposta, subordinada inteiramente a uma função de mediação didática e determinada pelos imperativos que decorrem desta função, como se vê através destes produtos e destes instrumentos característicos constituídos pelos programas e instruções oficiais, manuais e materiais didáticos, temas de deveres e de exercícios, controles, notas, classificações e outras formas propriamente escolares de recompensas e de sanções.

Desse modo, o processo de escolarização da RSE pode ser compreendido como um dispositivo que objetiva inculcar determinado conjunto de saberes, de conhecimentos. Esse conjunto de comportamentos a ser inculcado busca ser uma espécie de reatualização que remete aos princípios e ideais do fundador Dom Bosco. Os livros didáticos são instrumentos indispensáveis na efetivação da Proposta Pedagógica dos salesianos:

O material didático da RSE assume em todos os sentidos um papel fundamental nesse Projeto, por se tratar de um dos instrumentos principais para sua implantação, além de suscitar a formação continuada dos professores e de garantir apropriação dos conhecimentos pelo aluno. A preocupação com os princípios aqui explicitados perpassa tudo o que é produzido para o professor e o aluno, de tal forma que o material didático torna visível, concretiza e confere unidade a este Marco Referencial (PROJETO PEDAGÓGICO, 2005, p. 25).

Nessa linha de pensamento, a produção da coleção de livros didáticos está diretamente inserida no processo de ensino e aprendizagem do cotidiano escolar, quer dizer, nos dispositivos de escolarização. Ou, ainda, com base em Foucault (1990, p. 105), a organização e estrutura da Rede pode igualmente ser vista como uma tecnologia de controle, do chamado poder disciplinar. Especificamente em relação ao livro didático de História, este passa a ser o 
norteador do currículo escolar, isto é, direciona os conhecimentos a serem ensinados nas escolas da Rede.

Todavia, há que se considerar, nesse processo, as leituras e representações, as apropriações feitas pelos sujeitos envolvidos. Chartier se refere à existência de uma espécie de disparidade entre o prescrito pelo livro, pelas normas e o modo como o professor se apropria do conjunto das informações por meio da utilização do livro.

Por um lado, a leitura é prática criadora, actividade produtora de sentidos singulares, de significações de modo nenhum redutíveis às intenções dos autores de textos ou dos fazedores de livros [...]. Por outro lado, o leitor é, sempre, pensado pelo autor, pelo comentador e pelo editor como devendo ficar sujeito a um sentido único, a uma compreensão correcta, a uma leitura autorizada. Abordar a leitura é, portanto, considerar, conjuntamente, a irredutível liberdade dos leitores e os condicionamentos que pretendem refreá-la (CHARTIER, 1990, p. 123).

Assim, nas diretivas de Chartier (1990, p. 123), procurou-se analisar não somente as "estratégias por intermédio das quais autores e editores tentavam impor uma ortodoxia do texto, uma leitura forçada”, mas também os usos e apropriações dos leitores, quais sejam, estudantes e professores.

\section{Diferentes apreensões em torno do livro didático}

Com base nas interações e embates entre diferentes culturas que convivem no interior do cotidiano escolar, são produzidos saberes e práticas referentes às disciplinas escolares, à organização do espaço e do tempo, aos métodos de ensino e ao sistema de avaliação.

Desse modo, o currículo da RSE e os livros didáticos são elaborados social e historicamente conforme o contexto político, social e educacional. A regulamentação e prescrições adaptadas pelos autores dos livros didáticos e pela equipe pedagógica da RSE compõem o currículo prescrito da Rede. Entretanto, é no currículo em ação, na observação das aulas, na análise dos Instrumentos de pesquisa que é possível identificar o acatamento de determinadas prescrições, pois o leitor tem uma liberdade de apropriação que não pode ser prevista a priori.

Em uma sociedade marcada por novas formas de comunicação, de acesso e apropriação do conhecimento, Caimi (2009, p. 65) destaca: 
Estudos recentes sobre os processos do pensar e do aprender, em suas diversas vertentes, acentuam o papel ativo dos sujeitos/alunos em seus percursos de aprendizagem e o protagonismo do professor na promoção de situações educativas que favoreçam o desenvolvimento de habilidades de pensamento, traduzidas na construção de competências cognitivas para o 'aprender a aprender', e que, ao mesmo tempo, possam educar os jovens com base nos valores contemporâneos.

Nesse sentido, considerando que os docentes e os estudantes são sujeitos ativos no processo de escolarização, importa pensar a forma como utilizam o livro didático e os significados que lhe atribuem. Todos os docentes usam o livro conforme prescrito pela Rede? Como os estudantes avaliam o livro didático? Por exemplo, a resposta de um dos estudantes: “Não utilizamos o livro, infelizmente”, indica para o não uso do livro didático por parte de um dos docentes em uma das escolas.

De modo geral, as narrativas dos estudantes indicam para aspectos da contribuição do livro didático na sua formação, conforme Gráfico 1.

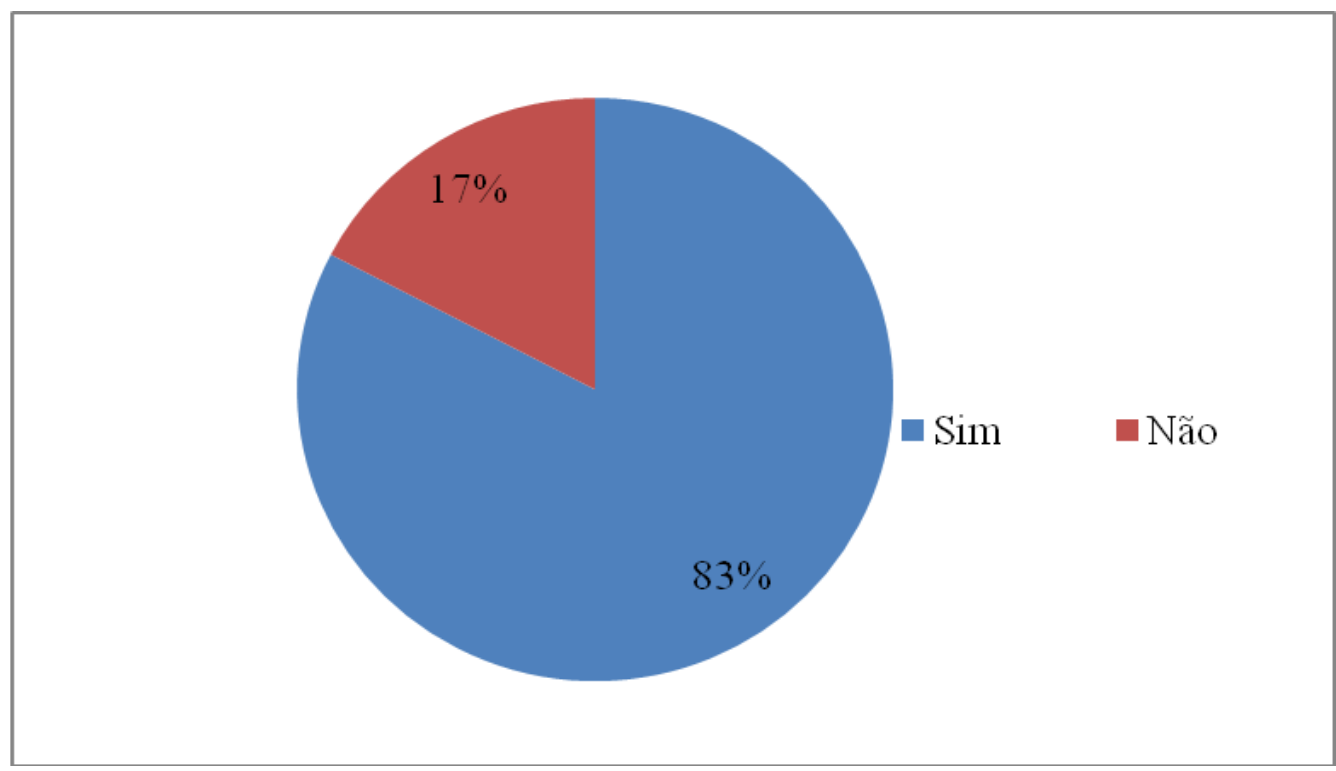

Gráfico 1 - Os conhecimentos adquiridos por meio do livro didático são importantes? Fonte: Instrumento de pesquisa respondido por 173 estudantes do ensino médio.

A maioria dos estudantes (83\%) entende o livro didático como um importante instrumento na aquisição de conhecimentos. Dentre os $17 \%$ que desconsideram sua importância, estão os seguintes argumentos:

Todo conhecimento sobre História é por meio de pesquisas por conta própria ou pela aula teórica do professor, mas não pelo conteúdo do livro [...]. Bom, o livro não é importante. Ele tenta, de forma diferenciada abordar os conteúdos e não segue a linearidade padrão, o que acaba tornando sua leitura trabalhosa, cansativa e algumas vezes incompreensível. História é muito 
importante, mas esta mensagem não é traduzida para os alunos por causa da abordagem inconstante do livro, o que gera ou agrava o usual desinteresse pelos materiais (Fragmentos das narrativas de 17\% dos estudantes).

Essas dificuldades apresentadas por esses estudantes se devem ao fato de a coleção não estar organizada, de modo a abordar os conteúdos históricos numa perspectiva cronológica linear. Há também o indicativo de que existem docentes que não adotam o livro como instrumento principal e/ou vão além dele, já que o conhecimento histórico é adquirido “por meio de pesquisas ou pela aula do professor".

O Professor IV muito bem discorre sobre a dificuldade de os estudantes pensarem fora de uma cronologia linear. Segundo ele, os jovens estudantes demonstram dificuldade em entender o conteúdo histórico organizado por temas, pois a coleção não segue uma cronologia linear ao tratar sobre a História. Compreender os processos históricos e as múltiplas temporalidades constitui-se, em sua opinião, em um grande desafio.

Nesse aspecto, aqui se podem visualizar algumas questões já problematizadas por estudiosos da área. De acordo com Schmidt e Cainelli (2004, p. 80), “o trabalho com a temporalidade no ensino da História não significa que o tempo seja, em si mesmo, o conteúdo a ser trabalhado, mas implica, sim, um pressuposto metodológico essencial para a compreensão e o raciocínio históricos”.

O Professor III, ao ser indagado se o livro didático da RSE do ensino médio possibilita, ao estudante, analisar situações históricas que estimulam o desenvolvimento do pensamento histórico, responde:

Pois é, aí está o problema, o livro é muito bom para os professores. Muitos alunos acabam sentindo dificuldades com a organização do texto e, devido a esta dificuldade (na narrativa mesmo) acabam tendo a análise dificultada. Aqueles que estão mais habituados à leitura conseguem sim fazer excelentes análises.

Essa narrativa complementa o que alguns estudantes salientaram sobre a dificuldade de entender a História pelo fato de o livro não estar organizado numa ordem cronológica linear. Além disso, remete ao comentário do Professor IV diante da dificuldade dos alunos em função de o livro não apresentar os assuntos numa cadeia sequencial.

Interessa aqui destacar que ambos sinalizam para a necessária mediação docente, em sala de aula, para o manuseio do livro. O Professor IV é de opinião que os autores partem do princípio de que o estudante já vem com um conhecimento prévio; porém, isso nem sempre se concretiza no cotidiano escolar, necessitando da ajuda do professor para mediar esse 
conhecimento. Essa mediação possibilita que o aluno se aproprie do conhecimento histórico e o compreenda como resultado de um trabalho de pesquisa. Esses indicativos se aproximam das questões investigadas por Bittencourt (2008, p. 216) a respeito da utilização de livros didáticos ao longo da história.

Existiram diferentes professores e diferentes práticas escolares. As formas de os professores se relacionarem com os textos didáticos variaram entre uma atitude de total dependência a outra que fazia do livro um objeto capaz de informá-lo, de atualizá-lo sobre o conhecimento a ser transmitido. Alunos e professores confrontavam-se na sala de aula, no espaço criado para transmitir o saber escolar.

Dentre os professores, as opiniões sobre a coleção são diversas. Ao serem indagados sobre se o livro didático orienta-os a considerar diferentes propostas explicativas de um conteúdo, dois deles respondem sim e três, parcialmente:

Os livros são bem estruturados, porém, se o professor não utilizar aulas expositivas esclarecendo aos alunos da estrutura que amarra as unidades e os capítulos com seus respectivos objetivos, os alunos não conseguem compreender a lógica que está por detrás dessa estrutura do livro (Professor IV).

Assim, pode-se visualizar que a formação do pensamento histórico não passa somente pela leitura do livro didático, mas, principalmente, pela mediação feita pelo professor.

Ao se considerar a dimensão das formas de consumo do livro didático, não se pode omitir o poder do professor. Cabe a este, na maioria das vezes, a escolha do livro, e sua leitura na sala de aula é determinada também pelo professor. Os capítulos selecionados, os métodos de leitura em grupo ou individual, assim como tarefas decorrentes da leitura, são opções exclusivas do professor, mesmo quando inseridas e limitadas por projeto pedagógico estipulado pela escola (BITTENCOURT, 2006, p. 74).

Conforme explicitado, os professores da RSE não escolhem o livro didático. São orientados pela equipe pedagógica da Rede e, ao mesmo tempo, pela coordenação pedagógica de cada escola a utilizar o livro na íntegra. Todavia, há incompatibilidade entre a quantidade de aulas semanais e a quantidade de conteúdos propostos nos livros didáticos. Esse é um dos principais fatores que dificulta o entendimento da estrutura dos conteúdos do livro didático.

O Professor III destaca: “acho o livro bem escrito e coerente, porém, não é o ideal para os alunos e o número de aulas que temos”. O Professor II salienta: “como fazer o que orientam os autores com a metade (ou menos) das aulas semanais previstas”? 
A fim de exemplificar essa questão, pode-se tomar o capítulo 4 do volume 2, intitulado: Terra e Poder na América Latina. De acordo com o Manual do Professor, o tempo sugerido para o estudo do capítulo é de dez aulas. Ou seja, ao se comparar com a média de aulas que cada escola possui, leva-se aproximadamente um mês para concluir o conteúdo. Numa espécie de lamento, o Professor III diz:

Desde o início fui entusiasta pelos livros da Rede por acreditar que eles contêm aquilo de mais atual que se discute em torno do ensino de História. Propõem discussões temáticas, conseguem, em alguns momentos, quebrar com a linearidade e incorporam discussões bastante atuais, como o livro do Segundo Ano, no capítulo que fala da terra no Brasil. Essa forma é clara para mim, como professor que tenho todo um arcabouço teórico para pensar a História. Para os alunos o livro se torna pesado.

Na análise das respostas à pergunta do Gráfico 2 é possível observar mais algumas representações construídas pelo uso do livro e também verificar em que medida a leitura é criativa e contribui na aquisição de conhecimento histórico.

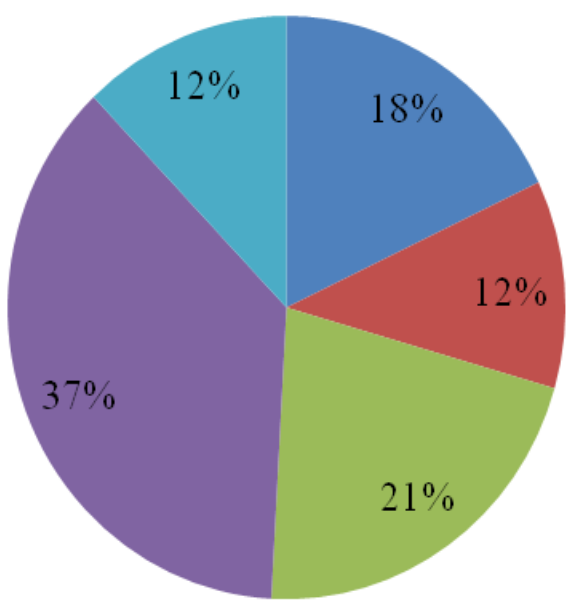

Gráfico 2 - Você lê o livro didático de História para:

Fonte: Instrumento de pesquisa respondido por 173 estudantes do ensino médio.
- Conhecer o seu passado e entender o seu presente.

- Preparar-se para a aula

- Formar uma opinião crítica a respeito de determinado assunto

- Estudar para prova

" Não lê

Dentre as respostas, "Estudar para a prova” e "Não lê” somam 49\%. A preocupação com a prova ou com o vestibular ainda é predominante nos alunos do ensino médio. Um realce é dado ao estudo e leitura do livro, tendo em vista o concurso vestibular e a entrada na universidade.

Dessa forma, grande parcela das narrativas dos estudantes vai na direção contrária ao pretendido pela coleção: 
Um investimento no estudo e na reflexão sobre as experiências sociais vividas diretamente pelos alunos, em seu tempo e em seu espaço, ou vividas por outros povos e grupos sociais, em outros tempos e outros espaços. Isso, para que se apropriem e utilizem com desenvoltura as noções e os conceitos necessários à análise, cada vez mais consistentes e autônomas, do presente e do passado (ROTA; MACHADO, 2009, p. 41).

Pode-se inferir que o exposto pelos autores não atinge plenamente os estudantes na medida em que eles atribuem outro sentido ao estudo da história: passar no vestibular.

Os autores da coleção também se manifestam a respeito da preocupação com o vestibular. O Autor $1 \mathrm{diz}$ que o livro foi pensando de forma intencional como instrumento que prepara para concursos, vestibular e ENEM. Opinião um tanto diferente tem o Autor II ao dizer que isso não é prioridade.

Minha compreensão da metodologia do ensino da História é a de que um trabalho consistente centrado nas habilidades de leitura / compreensão / interpretação / escrita, em várias linguagens, prepara o aluno para a cidadania e para os desafios intelectuais da vida, dentre os quais o vestibular. A opção por essa linha de trabalho implica, evidentemente, em fazer outros recortes de conteúdo, selecionar alguns temas para desenvolver e deixar outros de fora. Mas o aluno fica preparado para se apropriar, sozinho e com autonomia, de assuntos que ele não estudou na escola e, eventualmente, forem solicitados nos diversos vestibulares da vida. Mas não é essa a compreensão da maioria dos professores da Rede, para esses, é preciso ensinar tudo, isto é, "explicar" todo o programa do vestibular da região para o aluno, de um modo, inclusive, um tanto paternalista, fazendo todo o percurso por ele (Autor II).

De acordo com a narrativa do Autor II, há certa pressão à adequação do material para atender ao público interessado no vestibular.

Buscando identificar interesses para além do estudo em função do vestibular, em resposta a indagação do Gráfico 3, teve-se o seguinte resultado:

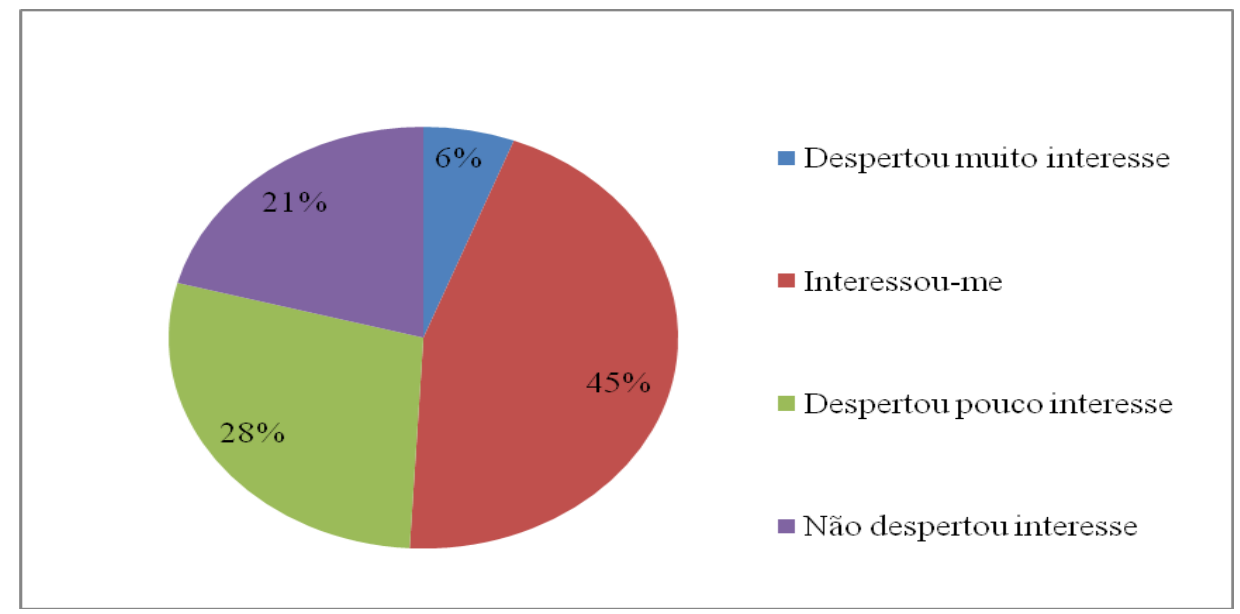

Gráfico 3 - A leitura do livro didático de História despertou em você o interesse para saber mais sobre o passado? Fonte: Instrumento de pesquisa respondido por 173 estudantes do ensino médio. 
Para 49\% dos estudantes o livro didático despertou pouco interesse ou não despertou interesse. Entendendo que a leitura do livro didático deve contribuir para a compreensão do passado interconectado ao presente e para a formação do pensamento histórico, quantidade significativa de estudantes, ainda não o compreende como um instrumento de aquisição de conhecimentos, produzidos e selecionados, sobre outros tempos.

Os estudantes assim escreveram:

(1) A autora, em muitas vezes, baseia-se em sua opinião e deixa de lado os conteúdos com visão para uma sala de aula; (2) Não gosto das opiniões expressas no livro, então, não absorvo o conteúdo através dele; (3) O livro apresenta muito a opinião da autora e o que eu preciso é de conteúdo (Narrativas de três estudantes).

Ao considerar que o livro didático é uma produção que envolve diferentes sujeitos até chegar ao aluno e professor, Chartier (1998, p. 77) declara que "apreendido pela leitura, o texto não tem de modo algum, ou ao menos totalmente, o sentido que lhe atribui seu autor, seu editor ou seus comentadores”, e que “toda história da leitura supõe, em seu princípio, esta liberdade do leitor que desloca e subverte aquilo que o livro lhe pretende impor”.

Constata-se que as apropriações sobre o livro didático podem variar de acordo com as representações que os professores fazem dele. Evidentemente que cada professor da RSE também atribui diferentes sentidos ao livro didático, sentidos que muitas vezes ainda estão atrelados a concepções já superadas, aquelas de o livro didático ser entendido como um vilão do processo de ensino da História, limitando a problematização e a criticidade dos fatos históricos.

Ainda, conforme Chartier (1990), os sentidos que os leitores dão ao texto advêm de seu sistema de representação, que é recorrente à sua cultura. No caso da leitura do livro didático por professores e estudantes, cada qual se apropria da leitura considerando as suas especificidades culturais. Entretanto, observou-se que o jovem estudante está mais suscetível à influência das apropriações e representações dos professores.

Nesse sentido, o lugar assumido pelo professor possibilita um entendimento das narrativas dos estudantes, pois se verifica que eles levam em consideração a postura do professor em relação ao livro. Ao analisar os dados específicos das duas escolas nas quais o Professor I e o Professor II exercem a docência, é importante ressaltar os dados dos Gráficos 4 e 5. 


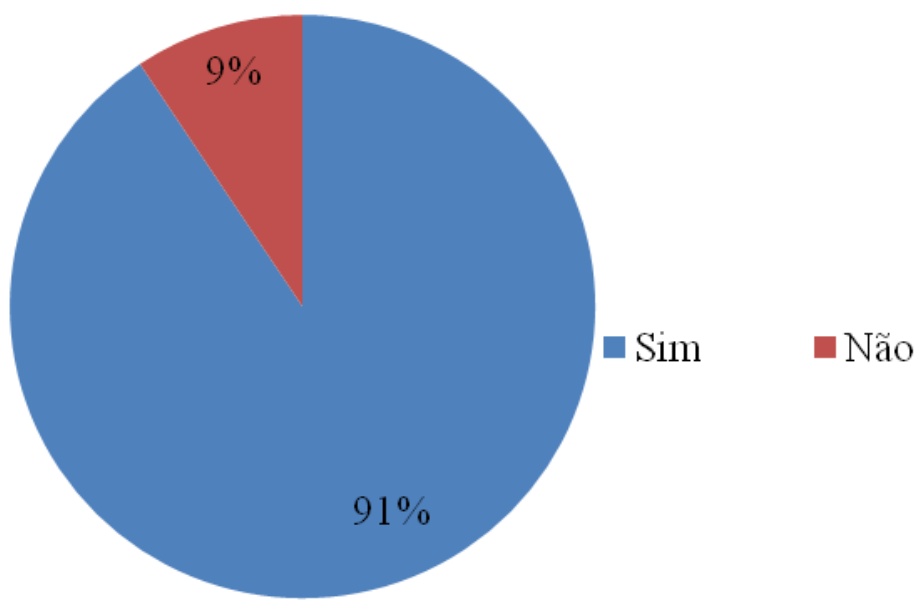

Gráfico 4 - Os conhecimentos adquiridos por meio do livro didático são importantes? Fonte: Instrumento de pesquisa respondido pelos estudantes da Escola do Professor I.

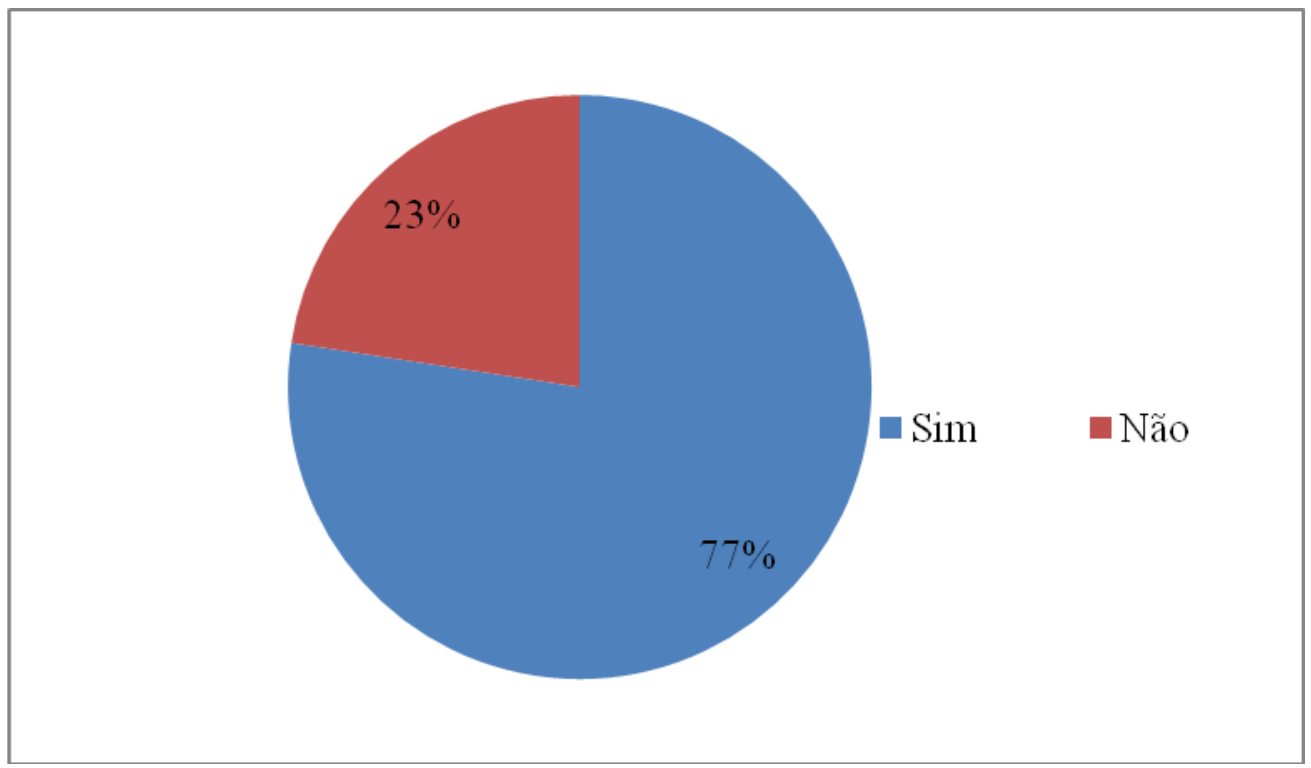

Gráfico 5 - Os conhecimentos adquiridos por meio do livro didático são importantes? Fonte: Instrumento de pesquisa respondido pelos estudantes da Escola do Professor II.

Coincidentemente, a percentagem de respostas em relação à aquisição de conhecimentos pelo livro didático se aproxima da percentagem de aprovação para mais e para menos do Professor I e II, respectivamente.

Assim sendo, pode-se observar que as representações não são discursos neutros, elas influem na opinião de uns e de outros, professores e estudantes. A aprovação da coleção por parte do professor está diretamente relacionada a uma escolha de compactuar com a proposta da instituição ou não. Nessa perspectiva, as representações dos alunos no que se refere ao 
conhecimento histórico do livro didático são apropriadas de formas diversas, em grande medida, por influência do que os professores pensam relativamente ao livro.

\section{Considerações}

Na Rede Salesiana de Escolas o livro didático é parte integrante dos dispositivos curriculares e é tomado pela Instituição como o principal recurso metodológico dos docentes. Todavia, é nos processos de mediação didática, ainda a ser investigados com maior acuidade, que se observa a importância atribuída a esse material.

A mediação didática aqui é compreendida na conceituação utilizada por Lopes (1997, p. 106), em seu sentido dialético, como "um processo de constituição de uma realidade por meio de mediações contraditórias, de relações complexas, não imediatas, com um profundo sentido de dialogia”. Nessa direção, o mais importante não está em identificar se o livro didático como tal contribui na formação do pensamento histórico, haja vista que a questão central é analisar os usos do livro e os processos de apropriação do conhecimento histórico por meio dele veiculado.

Há que se destacar que o livro didático por si só não dá conta de tratar da historicidade dos conceitos, da problemática em torno das diferentes formas de apreensão do conhecimento. Assim como os autores do livro devem elucidar as fontes com base nas quais construíram determinada narrativa histórica, os docentes e estudantes, se utilizarem o livro tendo consciência de que o conhecimento foi produzido por alguém em um tempo e espaço, não estarão isolando a História dos caminhos de sua produção. Exatamente aqui se pode visualizar a constituição do pensamento histórico.

Dessa maneira, o uso cotidiano do livro e o ensino de tudo o que seus autores selecionaram como legítimo a ser ensinado, não garantem, por si só, a formação do pensamento histórico. As representações dos professores repercutem diretamente na representação dos estudantes acerca do livro didático. Muito embora a RSE, desde 2002, tenha criado mecanismos de modo a conduzir todas as escolas salesianas do Brasil a uma unidade, mesmo em um único Estado, observou-se uma diversidade de práticas relativas ao uso do material. Obviamente, por si só, isso não é indício de não unidade.

Se por um lado, as prescrições da RSE apontam para uma ênfase no conteúdo associada a uma lógica da produtividade, por outro, essa mesma lógica pode ser a responsável por dificultar a dinâmica da formação e desenvolvimento do pensamento histórico. 
Diante disso, os desafios continuam e parece que uma das lacunas está numa espécie de disjunção entre as categorias tratadas por Reinhart Koselleck, experiência e expectativa. Assim, um dos passos é seguir compreendendo os processos de seleção do que se elege como saber a ser ensinado e a mediação didática, essencial no processo escolar. Para tanto, a abertura para a indicação de Koselleck pode ser inspiração para tal proposta, ao afirmar (2006, p. 313) que “é a tensão entre experiência e expectativa que, de uma forma sempre diferente, suscita novas soluções, fazendo surgir o tempo histórico”.

\section{Referências}

BITTENCOURT, Circe Maria Fernandes. Livro didático e saber escolar (1810-1910). Belo Horizonte: Autêntica, 2008.

. O saber histórico na sala de aula. 11. ed. São Paulo: Contexto, 2006.

BISEWSKI, Osvaldo. Práticas de formação continuada de professores: estudo de caso na rede Salesiana de Escolas. 2008. 100 f. Dissertação (Mestrado em Educação nas Ciências). Universidade do Noroeste do Estado do Rio Grande do Sul, Rio Grande do Sul.

CAIMI, Flávia Eloisa. História escolar e memória coletiva: como se ensina? Como se aprende? In: ROCHA, Helenice Aparecida Bastos; MAGALHÃES, Marcelo de Souza; GONTIJO, Rebeca. (Org.). A escrita da história escolar: memória e historiografia. Rio de Janeiro: FGV, 2009, p. 65-79.

CASSIANO, Célia Cristina de Figueiredo. Mercado do livro didático no Brasil: do Programa Nacional do Livro Didático à entrada do capital internacional espanhol (1985 a 2007). Tese (Doutorado em Educação). PUC, São Paulo, 2007.

CHARTIER, Roger. A aventura do livro: do leitor ao navegador. Tradução: Reginaldo Carmello Corrêa de Moraes. São Paulo: Unesp, 1998.

. À beira da falésia: a história entre certezas e inquietudes. Tradução: Patrícia Chittoni Ramos. Porto Alegre: UFRGS, 2002.

. A ordem dos livros: leitores, autores e bibliotecas na Europa entre os séculos XIV e XVIII. Tradução: Mary Del Priore. Brasília: Unb, 1999.

. A história cultural: entre práticas e representações. Tradução: Maria Manuel Galhardo. Lisboa: Difel, 1990.

CHERVEL, André. História das disciplinas escolares: reflexões sobre um campo de pesquisa. Teoria \& Educação. Porto Alegre: n. 2, p. 177-229, 1990.

FORQUIN, Jean-Claude. Saberes escolares, imperativos didáticos e dinâmicas sociais. Teoria \& Educação, Porto Alegre, n. 5, p. 28-49, 1992. 
FOUCAULT, Michel. Microfísica do poder. 9. ed. Tradução: Roberto Machado. Rio de Janeiro: Graal, 1990.

GRANGEIRO, Cândido Domingues; MACHADO, Ronilde Rocha. História: ensino médio, $2^{\circ}$ ano. Brasília: CIB - Cisbrasil, 2005. (Coleção RSE, MH2A).

. História: ensino médio, $3^{\circ}$ ano. Brasília: CIB - Cisbrasil, Brasília: 2006. (Coleção RSE, MH3A).

JULIA, Dominique. A cultura escolar como objeto histórico. Revista Brasileira de História da Educação. Campinas: n. 1, p. 9-44, 2001.

KOSELLECK, Reinhart. Futuro Passado: contribuição à semântica dos tempos históricos. Tradução: Wilma Patrícia Maas e Carlos Almeida Pereira. Rio de Janeiro: Contraponto; PUC, 2006.

LOPES, Alice Casimiro. Conhecimento escolar: processos de seleção cultural e de mediação didática. Educação \& Realidade. Rio Grande do Sul: 22(1): 95-112, jan/jun 1997.

MAGALHÃES, Justino. O manual escolar no quadro da história cultural: para uma historiografia do manual escolar em Portugal. Sísifo. Revista de Ciências da Educação, Lisboa, n. 1, p. 5-14, set./dez./2006.

ROCHA, Helenice Aparecida Bastos; MAGALHÃES, Marcelo de Souza; GONTIJO, Rebeca. (Org.). A escrita da história escolar: memória e historiografia. Rio de Janeiro: FGV, 2009.

ROTA, Paulo Jorge Storace; MACHADO, Ronilde Rosa. História: ensino médio, $1^{\circ}$ ano. 2. ed. Brasília: CIB - Cisbrasil, 2009. (Coleção RSE, MH1A).

SCHMIDT, Maria Auxiliadora; CAINELLI, Marlene. Ensinar história. São Paulo: Scipione, 2004.

VEIGA, Cynthia Greive. A escolarização como projeto de civilização. Revista Brasileira de Educação. Rio de Janeiro: Anped, n. 21, p. 90-103, set/ out/ nov/ dez 2002.

Recebido em: 19/05/2012

Aprovado em: 08/10/2012 